\title{
The effects of consumption of raw garlic on serum lipid level, blood sugar and a number of effective hormones on lipid and sugar metabolism in hyperglycemic and/or hyperlipidemic individuals
}

\author{
_-Benefit of raw garlic consumption
}

\author{
M. Mahmoodi ${ }^{\text {* }}$, S. M. Hosseini Zijoud ${ }^{1}$, G. H. Hassanshahi ${ }^{2}$, M. A. Toghroli ${ }^{1}$, M. Khaksari ${ }^{3}$, \\ M. R. Hajizadeh ${ }^{1}$, E. Mirzajani ${ }^{4}$ \\ ${ }^{1}$ Department of Biochemistry, Faculty of Medicine, Rafsanjan University of Medical Sciences, Rafsanjan, Iran;
${ }^{2}$ Molecular Medicine Research Center, Rafsanjan University of Medical Sciences, Rafsanjan, Iran;
${ }^{3}$ Physiology Research Center, Kerman University of Medical Sciences, Kerman, Iran;
${ }^{4}$ Department of Biochemistry, Faculty of Medicine, Rasht University of Medical Sciences, Rasht, Iran.
Email: " mahmoodies@yahoo.com
}

Received 2 July 2011; revised 4 August 2011; accepted 11 August 2011.
Keywords: Garlic; Serum Lipid Level; Blood Sugar; Hormones; Hyperglycemic; Hyperlipidemic

\section{INTRODUCTION}

Elevated lipid and sugar levels are amongst the most important complications in cardiovascular disorders and diabetes. Diabetes mellitus is known as the most growing metabolic disease that characterized by altered carbohydrate, lipid and protein metabolism [1], and in parallel with advancing in knowledge on the heterogeneity of this disorder, the need for more appropriate therapy increases [2]. Increasing level of lipid leads to cardiovascular diseases and stroke. The underlying mechanism is increased LDL cholesterol, which further undergoes oxidative modification in the presence of free radicals [3]. The decrease LDL level with raised HDL cholesterol play important role against these complications. Due to the highly costs for synthetic drugs, probable side effects of this drugs and also restrictions in use of these drugs, during recent years scientists and researcher trying to substitute herbal plant and some natural component in these plants for treatment of disease.

It is well established that consumption of fruit and vegetables prevents some diseases [4]. Among vegetables, garlic is one of the most important ones [5,6]. Garlic (Allium sativum) is a member of the Liliaceae family, which is one of the most popular herbs used worldwide to reduce various risk factors associated with several diseases [7]. It has been reported that garlic and onions are effective in preventing cardiovascular diseases due to their hypocholesterolemic, hypolipidemic, antihyperten- 
sive, antidiabetic, antithrombotic and antihyperhomocysteinemia effects [8]. These vegetables also have antimicrobial, antioxidant, anticarcinogenic, antimutagenic, antiasthmatic and immuno-modulatory activities $[9,10]$ Some studies confirmed anti-hyperglycemic [11] effects of garlic. The hypoglycemic potency of garlic has been attributed mainly to allicin and its derived sulphur compounds [12]. Amelioration of atherosclerosis by garlic (Allium sativum) was also evidenced in both human $[13,14]$ and experimental animal models [15]. We have previously shown that consumption of raw garlic had hypolipidemic and hypoglycemic effects [16].

Other study suggested that garlic supplementation significantly reduced serum glucose but increased serum insulin and liver glycogen [17]. Investigations suggested that garlic reduces lipid synthesis and influenced glycogen metabolism in the liver of rats [17]. The hypoglycemic effect of garlic seems to be associated with the elevation of insulin level. The increased insulin response also promotes the conversion of the inactive form of glycogen synthetase to the active and enhances conversion of blood glucose into glycogen [17]. Therefore, it is clear that hormones are one of the most effective factors in reduction of blood lipid and sugar. Furthermore, because to date, hormonal surveys have reported only on animal experiments, thus, we designed the current study to measure factors such as FBS, cholesterol, TG, HDL-C and LDL-C, thyroids hormones (T3, T4, TSH) and insulin in hyperglycemic and/or hyperlipidemic individuals to find out the possible pathways that garlic may control on sugar and lipid metabolism.

\section{MATERIALS AND METHODS}

In this clinical survey, 85 volunteers that have been informed of the aim of the experiment of method divided in to three groups following enter to the study.

Group 1: Volunteers with FBS (fasting blood sugar) more than $126 \mathrm{mg} / \mathrm{dl}$ (30 people, 17 female and 13 male, mean ages $45.2 \pm 9.2$ ).

Group 2: Volunteers with cholesterol higher than 245 $\mathrm{mg} / \mathrm{dl}$ (30 people, 19 female and 11 male, mean ages 42 $\pm 6.1)$.

Group 3: This group included volunteers with BS more than $126 \mathrm{mg} / \mathrm{dl}$ and cholesterol higher than 245 $\mathrm{mg} / \mathrm{dl}$ ( 25 people, 17 female and 8 male, mean ages 46.2 $\pm 7.4)$.

All groups had normal diet and weren't using any sugar or lipid reducer drugs and also were matched for age and body mass index (BMI). All of volunteers take part in the study with completely satisfaction and awareness. Initially, fasting blood samples were collected and biochemical and hormonal factors were measured. Garlic units were supplied, and were used for 42 days (10 $\mathrm{gr} / \mathrm{day}$, in 2 meals) by volunteers and the study was followed by second blood samples collection and assessment of the biochemical factors. Afterward, volunteers didn't take garlic for 6 weeks and then the third fasting blood samples were collected and biochemical factors were measured. Measured biochemical factors were: FBS, total cholesterol, HDL-C, LDL-C and TG that assayed by BT-3000 auto-analyzer apparatus and glycated hemoglobin was measured by chromatography. The level of thyroids hormones T3, T4 and TSH and insulin were quantified by gamma-counter machine using RIA or IRMA method. Data were analyzed by SPSS software version 13 and where $P$ value was less than 0.05 , the differences was considered as significant.

\section{RESULTS AND DISCUSSION}

In the first group (30 volunteers with FBS more than 126 $\mathrm{mg} / \mathrm{dl}$ ) the averages of the measured factors in three steps were compared and didn't show any significant differences (Table 1).

In the second group (30 volunteers with blood cholesterol over $245 \mathrm{mg} / \mathrm{dl}$ ), following 42 days garlic consumption had significant decrease in the level of FBS ( $P$ $<0.01)$, total cholesterol $(P<0.001)$ and TG $(P<0.01)$ and after 42 days of stopping garlic consumption as a part of daily diet FBS and TG elevated while HDL-C average decreased. Other measured biochemical factors and hormones shown no significant differences (Table 2). The third group (25 volunteers with FBS more than $126 \mathrm{mg} / \mathrm{dl}$ and blood cholesterol higher than $245 \mathrm{mg} / \mathrm{dl}$ ), following 42 days using garlic the level of FBS $(P<$ $0.01)$ and also total cholesterol $(P<0.001)$ were significantly decreased. Glycated hemoglobin significantly decreased $(P<0.01)$ as well as FBS $(P<0.01)$. The HDL-C level significantly increased after 42 days garlic consumption (Table 3). In this group similarly as other group we couldn't find any significant changes in hormones level.

In this study, following 42 days garlic consumption (10 grams daily), blood cholesterol decreased in the second and third group which was statistically significant $(P<0.001)$, but there isn't any significant differences in biochemical factors in first groups that we can conclude garlic has more effect on lipid profile than glucose as previous studies demonstrated too $[6,13,15,16]$. These findings were consistent with Kannar et al, results that showed using garlic for 12 weeks decreased total cholesterol and LDL-C about $4.2 \%$ and $6.6 \%$ respectively [18]. In our study after garlic consumption, HDL-C was increased significantly while LDL-C and TG didn't show a significant change. Morcos NC reported that consumption of fish oil and garlic decreased serum cholesterol and TG about $11 \%$ and $34 \%$, respectively [19]. Some other studies evidenced that garlic didn't have any 
Table 1. Comparison of measured biochemical factors \& hormones in 3 steps of study in group with FBS more than $126 \mathrm{mg} / \mathrm{dl}$ ( $\mathrm{n}=$ $30, \mathrm{~F}=17, \mathrm{M}=13$, mean age $=45.2 \pm 9.2$ ).

\begin{tabular}{cccc}
\hline Blood Factor & $\begin{array}{c}\text { Step 1 } \\
\text { mean } \pm \text { SEM }\end{array}$ & $\begin{array}{c}\text { Step 2 } \\
\text { mean } \pm \text { SEM }\end{array}$ & $\begin{array}{c}\text { Step 3 } \\
\text { mean } \pm \text { SEM }\end{array}$ \\
\hline FBS $(\mathrm{Mg} / \mathrm{dl})$ & $174.17 \pm 6.9$ & $164.4 \pm 7.3$ & $175.5 \pm 8.1$ \\
Glycated Hemoglobin $(\%)$ & $8.3 \pm 0.18$ & $7.9 \pm 0.21$ & $8.1 \pm 0.17$ \\
Insulin $(\mu \mathrm{IU} / \mathrm{ml})$ & $10.47 \pm 3.8$ & $9.28 \pm 3.1$ & $9.1 \pm 3.5$ \\
TSH $(\mathrm{ng} / \mathrm{ml})$ & $1.8 \pm 0.56$ & $1.8 \pm 0.6$ & $1.87 \pm 0.7$ \\
T3 $(\mathrm{ng} / \mathrm{ml})$ & $1.9 \pm 0.53$ & $1.9 \pm 0.45$ & $1.7 \pm 0.32$ \\
T4 $(\mathrm{ng} / \mathrm{ml})$ & $118 \pm 54.6$ & $111 \pm 43.6$ & $110 \pm 43.2$ \\
Total cholesterol $(\mathrm{Mg} / \mathrm{dl})$ & $207.8 \pm 5.01$ & $195.3 \pm 4.5$ & $207.03 \pm 5.9$ \\
HDL-C $(\mathrm{Mg} / \mathrm{dl})$ & $42.5 \pm 0.9$ & $44.4 \pm 1.01$ & $43.1 \pm 0.8$ \\
LDL-C $(\mathrm{Mg} / \mathrm{dl})$ & $99.5 \pm 2.5$ & $100.2 \pm 2.3$ & $104 \pm 2.5$ \\
TG $(\mathrm{Mg} / \mathrm{dl})$ & $154.3 \pm 10.7$ & $145.3 \pm 08.2$ & $156 \pm 9.6$ \\
\hline
\end{tabular}

Step 1: at the beginning of study;

Step 2: 42 days after garlic consumption;

Step 3: 42 days after stopping of garlic consumption.

Table 2. Comparison of measured biochemical factors \& hormones in 3 steps of study in group with blood cholesterol more than $245 \mathrm{mg} / \mathrm{dl}(\mathrm{n}=30, \mathrm{~F}=19, \mathrm{M}=11$, mean age $=42 \pm 6.1)$.

\begin{tabular}{|c|c|c|c|}
\hline Blood Factor & $\begin{array}{c}\text { Step 1 } \\
\text { mean } \pm \text { SEM }\end{array}$ & $\begin{array}{c}\text { Step } 2 \\
\text { mean } \pm \text { SEM }\end{array}$ & $\begin{array}{c}\text { Step } 3 \\
\text { mean } \pm \text { SEM }\end{array}$ \\
\hline FBS $(\mathrm{Mg} / \mathrm{dl})$ & $99.6 \pm 2.02$ & $92.9 \pm 2.2 \quad \mathrm{a}^{* *}$ & $98.5 \pm 2.4 \quad b^{*}$ \\
\hline Glycated Hemoglobin (\%) & $5.64 \pm 0.14$ & $5.67 \pm 0.09$ & $5.76 \pm 0.09$ \\
\hline Insulin $(\mu \mathrm{IU} / \mathrm{ml})$ & $6.7 \pm 2.18$ & $6.9 \pm .2$ & $6.5 \pm 1.6$ \\
\hline TSH (ng/ml) & $1.93 \pm 1.2$ & $1.8 \pm 1$ & $1.96 \pm 0.8$ \\
\hline $\mathrm{T} 3$ (ng/ml) & $1.95 \pm 0.48$ & $1.86 \pm 0.32$ & $1.85 \pm 0.43$ \\
\hline $\mathrm{T} 4$ (ng/ml) & $126.5 \pm 26$ & $117 \pm 24$ & $117 \pm 32$ \\
\hline Total cholesterol $(\mathrm{Mg} / \mathrm{dl})$ & $278.5 \pm 4.7$ & $248.4 \pm 50.2 \quad \mathrm{a}^{* * *}$ & $256.9 \pm 5.8 \quad b^{* * *}$ \\
\hline HDL-C (Mg/dl) & $44 \pm 1.2$ & $48.1 \pm 1.3 \quad \mathrm{a}^{* * *}$ & $43.4 \pm 0.8$ \\
\hline LDL-C (Mg/dl) & $103.6 \pm 3.03$ & $101.1 \pm 2.35$ & $106.9 \pm 2.2$ \\
\hline TG $(\mathrm{Mg} / \mathrm{dl})$ & $227.1 \pm 19.5$ & $189.4 \pm 16.2 \quad \mathrm{a}^{* *}$ & $212.1 \pm 16.2 \quad b^{*}$ \\
\hline
\end{tabular}

Step 1: at the beginning of study;

Step 2: 42 days after garlic consumption;

Step 3: 42 days after stopping of garlic consumption;

a: Signification differences in the second step compare to the first step;

b: Signification differences in the third step compare to the second step;

$*: P<0.05 ; * *: \mathrm{P}<0.01 ; * * *: P<0.001$.

Table 3. Comparison of measured biochemical factors \& hormones in 3 steps of study in group with FBS more than $126 \mathrm{mg} / \mathrm{dl}$ and blood cholesterol more than $245 \mathrm{mg} / \mathrm{dl}(\mathrm{n}=25, \mathrm{~F}=17, \mathrm{M}=8$, mean age $=46.2 \pm 7.4)$.

\begin{tabular}{|c|c|c|c|}
\hline Blood Factor & $\begin{array}{c}\text { Step } 1 \\
\text { mean } \pm \text { SEM }\end{array}$ & $\begin{array}{c}\text { Step } 2 \\
\text { mean } \pm \text { SEM }\end{array}$ & $\begin{array}{c}\text { Step } 3 \\
\text { mean } \pm \text { SEM }\end{array}$ \\
\hline FBS (Mg/dl) & $181.4 \pm 12.5$ & $163.3 \pm 10.5 \quad a^{* *}$ & $98.5 \pm 11.6$ \\
\hline Glycated Hemoglobin (\%) & $8.1 \pm 0.37$ & $7.8 \pm 34 \quad a^{*}$ & $7.7 \pm 0.3$ \\
\hline Insulin $(\mu \mathrm{IU} / \mathrm{ml})$ & $8.9 \pm 6.3$ & $8.7 \pm 5$ & $6.8 \pm 3.6$ \\
\hline TSH (ng/ml) & $2.47 \pm 0.36$ & $2.47 \pm 1.49$ & $2.8 \pm 0.9$ \\
\hline $\mathrm{T} 3(\mathrm{ng} / \mathrm{ml})$ & $2 \pm 0.8$ & $1.9 \pm 0.7$ & $2 \pm 0.62$ \\
\hline $\mathrm{T} 4$ (ng/ml) & $92 \pm 31.2$ & $84 \pm 27.4$ & $98 \pm 25.5$ \\
\hline Total cholesterol (Mg/dl) & $272.08 \pm 6.3$ & $251.52 \pm 6.3 \quad \mathrm{a}^{* * *}$ & $260.52 \pm 6.7$ \\
\hline HDL-C (Mg/dl) & $42.5 \pm 0.9$ & $43,6 \pm 1.8 \quad a^{*}$ & $44.6 \pm 0.8$ \\
\hline LDL-C (Mg/dl) & $126.08 \pm 5.5$ & $122.7 \pm 4.8$ & $127.5 \pm 4.5$ \\
\hline TG $(\mathrm{Mg} / \mathrm{dl})$ & $211.8 \pm 16.7$ & $220 \pm 21.6$ & $195.6 \pm 12.7$ \\
\hline
\end{tabular}

Step 1: at the beginning of study;

Step 2: 42 days after garlic consumption;

Step 3: 42 days after stopping of garlic consumption;

a: Signification differences in the second step compare to the first step;

$*: P<0.05 ; * *: P<0.01 ; * * *: P<0.001$. 
significant impression on serum TG [20]. Beside of this hypolipidemic effect of garlic, in present study, we observed significant reduction of FBS and $\mathrm{HbAlC}$ in the second and third groups $(P<0.01)$, that is in consistence with Ahmed and Sharma who reported that using of garlic oil decreases FBS in rats [21]. We didn't observe any significant changes in the level of T3, T4 and TSH hormones during the three steps of our study. No relation found between thyroid hormones and blood lipid in other similar studies [22].

We didn't find a relative previous study about the effect of garlic consumption on thyroid hormones in database to compare with our study.

In this study we assessed the hormonal effect of garlic because previous studies showed some of these effects. The study have suggested that garlic supplementation enhances protein anabolism and suppresses protein catabolism (due to hormonal regulation by the stimulation of steroid hormones), thus, leading to greater testis testosterone content and lower plasma corticosterone concentration in rats treated with a high protein diet [23].

Further to thyroid hormones we measured the insulin levels in the study and didn't observe any significant change.

Insulin plays a key role in the metabolism of lipids apart from its regulatory effects on carbohydrate metabolism.

Many studies imply the antioxidant and insulinoid effects of some trace elements like selenium, germanium and vitamin $\mathrm{C}$ which all found in garlic [24].

Clinically probably, we can conclude that using garlic in long term causes decreased cholesterol and FBS level possibly by distinct hormonal mechanisms, as it was proved in many investigations similar to the present study but we didn't observe any change in hormones' level. According to the slightly side effects of garlic, it can possibly be used as an auxiliary medicine for hypercholesterolemic and hyperglysemic treatment.

It was shown that consumption of fruit and vegetables prevents some diseases [4]. Garlic has been recognized since ancient times not only as a flavoring agent for food but also for its medicinal properties, including bactericidal, antineoplastic, hypolipidemic, hypocholesterolemic and hypoglycemic effects [25].

In conclusion as reflected by other studies our results shown that raw garlic consumption can reduce the FBS and Lipid in hyperglycemic and/or hyperlipidemic individuals but in the period of this study we had not found any significant changes in measured hormones. In future we think if another study with longer duration would be carried out on the effects of garlic on hormones a differences may be observed.

These results are in consistent with several clinical reports, including meta-analyses, that have revealed hypoglycemic and hypolipidemic effects of garlic supplementation in humans. Consequently, authors of this article suggest that garlic may be prescribed in $10-20$ gr daily dosage as a supportative treatment in with little side effects for diabetic and hyperlipidemic patients.

\section{ACKNOWLEDGEMENTS}

The reported work was supported by Rafsanjan University of Medical Sciences.

\section{REFERENCES}

[1] Mutalik, S., Sulochana, B., Chetana, M., Udupa, N., Uma Devi, P. (2003) Preliminary studies on acute and subacute toxicity of an antidiabetic herbal preparation, Dianex. Indian Journal of Experimental Biology, 41, 316-320.

[2] Bailey, C.J., Flatt, P.R., Deacon, C.F., Shaw, C. and Conlon, J.M. (1986) Substance P, neurokinin A, vasoactive intestinal polypeptide and gastrin releasing peptide in the intestine and pancreas of spontaneously obese-diabetic mice. Regulatory Peptides, 16, 339-348. doi:10.1016/0167-0115(86)90034-0

[3] Agardh, C.D., Bjorgell, P. and Nilsson-Ehle, P. (1999) The effects of tolbutamide on lipoproteins, lipoprotein lipase and hormone-sensitive lipase. Diabetes Research and Clinical Practice, 46, 99-108. doi:10.1016/S0168-8227(99)00088-1

[4] Dauchet, L., Amouyel, P., Hercberg, S. and Dallongeville, J. (2006) Fruit and vegetable consumption and risk of coronary heart disease: a meta-analysis of cohort studies. Journal of Nutrition, 136, 2588-2593.

[5] Sanz, M.L., del Castillo, M.D., Corzo, N. and Olano, A. (2000) Presence of 2-furoylmethyl derivatives in hydrolysates of processed tomato products. Journal of Agricultural and Food Chemistry, 48, 468-471. doi:10.1021/jf990697b

[6] Gorinstein, S., Leontowicz, H., Leontowicz, M., Drzewiecki, J., Najman, K., Katrich, E., et al. (2006) Raw and boiled garlic enhances plasma antioxidant activity and improves plasma lipid metabolism in cholesterol-fed rats. Life Sciences, 78, 655-663. doi:10.1016/j.1fs.2005.05.069

[7] Fagbemi, A.A., Torrente, F., Hilson, A.J., Thomson, M.A., Heuschkel, R.B. and Murch, S.H. (2007) Massive gastrointestinal haemorrhage in isolated intestinal HenochSchonlein purpura with response to intravenous immunoglobulin infusion. European Journal of Pediatrics, 166, 915-919. doi:10.1007/s00431-006-0337-3

[8] Miranda-Vilela, A.L., Alves, P.C., Akimoto, A.K., Pereira, L.C., Nazare Klautau-Guimaraes, M.D. and Grisolia, C.K. (2010) The effect of hydrogen peroxide-induced oxidative stress on leukocytes depends on age and physical training in healthy human subjects carrying the same genotypes of antioxidant enzymes' gene polymorphisms. American Journal of Human Biology, 22, 807812. doi:10.1002/ajhb. 21086

[9] Utesch, D., Feige, K., Dasenbrock, J., Broschard, T.H., Harwood, M., Danielewska-Nikiel, B., et al. (2008) 
Evaluation of the potential in vivo genotoxicity of quercetin. Mutation Research, 654, 38-44.

[10] Omar, S.H., Radwan, K.G., Youssif, M.A., Khafagy, H.F., Kamal, N.M., El-Sabae, H.H., et al. (2009) A non-opioid fast track anesthetic regimen for colonic resection. Journal of the Egyptian Society of Parasitologyl, 39, 849-864.

[11] Eidi, A., Eidi, M. and Esmaeili, E. (2006) Antidiabetic effect of garlic (Allium sativum L.) in normal and streptozotocin-induced diabetic rats. Phytomedicine, 13, 624-629. doi:10.1016/j.phymed.2005.09.010

[12] Chang, M.L. and Johnson, M.A. (1980) Effect of garlic on carbohydrate metabolism and lipid synthesis in rats. Journal of Nutrition, 110, 931-936.

[13] Kojuri, J., Vosoughi, A.R. and Akrami, M. (2007) Effects of anethum graveolens and garlic on lipid profile in hyperlipidemic patients. Lipids in Health and Disease, 6, 5. doi:10.1186/1476-511X-6-5

[14] Butt, M.S., Sultan, M.T., Butt, M.S. and Iqbal, J. (2009) Garlic: nature's protection against physiological threats. Critical Reviews in Food Science and Nutrition, 49, 538-551. doi:10.1080/10408390802145344

[15] Asdaq, S.M., Inamdar, M.N. and Asad, M. (2009) Effect of conventional antihypertensive drugs on hypolipidemic action of garlic in rats. Indian Journal of Experimental Biology, 47, 176-181.

[16] Mahmoodi, M., Islami, M.R., Asadi Karam, G.R., Khaksari, M., Sahebghadam Lotfi, A., Hajizadeh, M.R., et al. (2006) Study of the effects of raw garlic consumption on the level of lipids and other blood biochemical factors in hyperlipidemic individuals. Pakistan Journal of Pharmaceutical Sciences, 19, 295-298.

[17] Villar-Palasi, C. and Larner, J. (1961) Insulin treatment and increased UDPG-glycogen transglucosylase activity in muscle. Archives of Biochemistry and Biophysics, 94, 436-442. doi:10.1016/0003-9861(61)90071-6
[18] Kannar, D., Wattanapenpaiboon, N., Savige, G.S. and Wahlqvist, M.L. (2001) Hypocholesterolemic effect of an enteric-coated garlic supplement. Journal of the American College of Nutrition, 20, 225-231.

[19] Morcos, N.C. (1997) Modulation of lipid profile by fish oil and garlic combination. Journal of the National Medical Association, 89, 673-678.

[20] Superko, H.R. and Krauss, R.M. (2000) Garlic powder, effect on plasma lipids, postprandial lipemia, low-density lipoprotein particle size, high-density lipoprotein subclass distribution and lipoprotein (a). Journal of the American College of Cardiology, 35, 321-326. doi:10.1016/S0735-1097(99)90541-7

[21] Ahmed, R.S. and Sharma, S.B. (1997)Biochemical studies on combined effects of garlic (Allium sativum Linn) and ginger (Zingiber officinale Rosc) in albino rats. Indian Journal of Experimental Biology, 35, 841-843.

[22] Chaudhuri, B.N., Mukherjee, S.K., Mongia, S.S. and Chakravarty, S.K. (1984) Hypolipidemic effect of garlic and thyroid function. Biomedica Biochimica Acta, 43, 1045-1047.

[23] Oi, Y., Imafuku, M., Shishido, C., Kominato, Y., Nishimura, S. and Iwai, K. (2001) Garlic supplementation increases testicular testosterone and decreases plasma corticosterone in rats fed a high protein diet. Journal of $\mathrm{Nu}$ trition, 131, 2150-156.

[24] Eriksson, J. and Kohvakka, A. (1995) Magnesium and ascorbic acid supplementation in diabetes mellitus. Annals of Nutrition and Metabolism, 39, 217-223. doi:10.1159/000177865

[25] Singh, A and Shukla, Y. (1998) Antitumor activity of diallyl sulfide in two-stage mouse skin model of carcinogenesis. Biomedical and Environmental Sciences, 11, 258-263. 